\title{
Exploring Renewable Energy in Food Supply Chain and Sustainable Marine Fishery with Sustainable Development Goals: Some Methodological Considerations
}

\author{
Dr. Suyu Liu"
}

${ }^{1}$ Food and Agriculture Organization of the United Nations, Rome, Italy

DOI: $10.36348 /$ sb.2022.v08i01.002 $\quad$ | Received: 13.12.2021 | Accepted: 16.01 .2022 | Published: 20.01 .2022

*Corresponding author: Dr. Suyu Liu

Food and Agriculture Organization of the United Nations, Rome, Italy

\section{Abstract}

From the angle of Sustainable Development Goals (SDGs), this research note explores renewable energy in food supply chain and sustainable marine fishery. With an initial theoretical analysis, it is observed that the share of renewable energy, as reflected by SDG Indicator 7.2.1, can contribute to the measurement of and data computation for SDG Indicators 12.3.1 and 14.7.1. This is because renewable energy becomes a significant component of on board cost for harvesting, processing, and preserving fishes by marine vessels/fleets. Also renewable energy can be used to estimate food waste because it functions as an estimation for municipal solid waste if data is not directly available. A number of scientific and practical implications are generated. For example, more interdisciplinary studies on the interactions across SDGs should be encouraged, and more in-depth empirical research are also expected in future. The connections between renewable energy, food supply chain, and sustainable marine fishery also call for more holistic policies for sustainable development, with adequate consideration of disparities in country contexts. Effective actions should be taken to further enhance the statistical capacities of countries and international organizations, which will be a foundation for applying more sophisticated techniques into the analysis of data in this field. The main objectives of this short research note are to provoke more scientific thoughts and provide policy-oriented recommendations. It leaves spaces for more empirical evidence-based future research including another study under the author's plan.

Keywords: Sustainable Development Goals; Renewable energy; Food supply chain; marine fishery.

Copyright $\odot 2022$ The Author(s): This is an open-access article distributed under the terms of the Creative Commons Attribution 4.0 International License (CC BY-NC 4.0) which permits unrestricted use, distribution, and reproduction in any medium for non-commercial use provided the original author and source are credited.

\section{INTRODUCTION}

Renewable energy is a key to achieve a number of goals in climate change and sustainable development. As demonstrated by the International Renewable Energy Agency (IRENA), the transition of energy sector grounded in more renewable sources and technologies would be important to achieve the $1.5^{\circ} \mathrm{C}$ Scenario (IRENA, 2021) [1]. In addition, renewable energy can generate positive impact on other aspects of sustainable development, especially in least developed countries (LDCs). For example, as illustrated by Karakezi and Kithyoma (2002), wide use of renewable energy technologies can contribute to rural development in sub-Sahara Africa [2]. This is particularly the situation in terms of providing more reliable energy supply to rural households and reducing the negative health impact of using traditional energy.
The importance of renewable energy has been particularly observed in the context of the COVID-19 pandemic, as the production and use of renewable energy are demonstrated with higher resilience than traditional energy (IRENA, 2020) [3]. For example, in comparison with the relatively labour-intensive traditional energy sector such as the production of fossil fuel, renewable energy sector may have higher technology intensity and is therefore less affected by the pandemic and relevant control measures. The advantages of using renewable energy, especially in supporting food supply and sustainable fishery, have been gradually noticed by both scientific researchers and practitioners, including international organizations such as Food and Agriculture Organization of the United Nations (FAO). This can be reflected by the partnership between FAO and IRENA to promote the 
use of renewable energy to boost agri-food and fishery supply chains (IRENA and FAO, 2021) [4].

Although the exact definition varies, it is widely perceived that food supply chain starts from the step of harvest or slaughter, and then moves to the onfarm post-harvest/slaughter operations as well as offfarm operations such as storage, packaging, and transport (FAO, 2021a) [5]. It then moves to the stage of consumption, including retailing and consumption by end-users such as organizations and households (FAO, 2021a) [5]. The whole food supply chain requires reliable supply of energy including renewable energy, and the cost of energy (especially renewable energy for some countries) can become a major burden for maintain the resilience of food supply chain (IRENA and FAO, 2021) [4]. Although previous studies contribute to the assessment of renewable energy in food supply chains at industrial and organizational level (e.g., Jensen and Govindan, 2014) [6], it is relatively more difficult to examine renewable energy in food supply chains at country level or even global level. This leaves spaces for this research note and calls for more in-depth empirical studies in future.

Although marine fishery is sometimes felt as a part of food supply chain, it has some differences with the perspective of renewable energy. For example, Basurko et al (2013) [7] explain that the disparities of marine fishing vessels/fleets and their fishing activities may become difficulties to the wide application of renewable energy on board, although the technological plausibility of on board use of renewable energy has been demonstrated by existing literature (e.g., Lu and Wang, 2016) [8]. Also, Liu (2022, forthcoming) argues that the promotion of use of renewable energy in marine fishery requires more integrated approaches with considerations of different aspects of sustainable development [9]. The Sustainable Development Goals (SDGs) may be used since they cover various dimensions of sustainable development and their possible interactions (e.g., Le Blanc, 2015) [10].

The 17 SDGs are the core of the 2030 Agenda for Sustainable Development, which was adopted by the United Nations (UN) in 2015 (UN, 2020) [11]. The SDGs call for collaborative actions to achieve peace, prosperity, and sustainability in both short and long terms. An example of the collaborative actions is the establishment of the Inter-agency and Expert Group on SDG Indicators (IAEG-SDGs), which contributes to the development of a global indicator framework of SDGs (IAEG-SDGs, 2021) [12]. Renewable energy, food supply chain, and marine fishery are all covered by different SDGs and indicators. As shown in Figure 1, the SDGs reflect different dimensions of sustainable development, which integrate and interact with each other, and should be considered as a whole rather than unrelated segments.

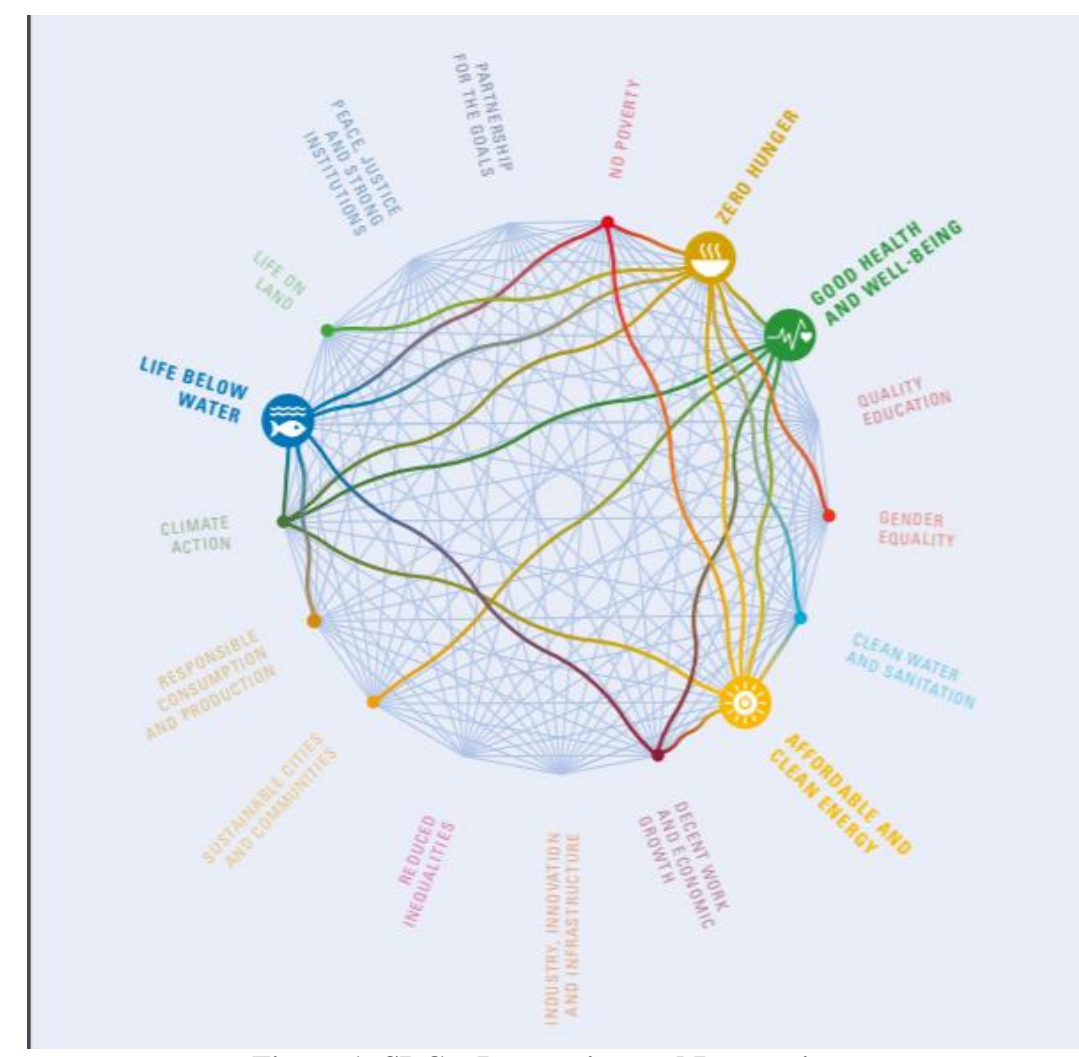

Figure 1: SDGs: Integration and Interactions

(Source: International Council for Science, 2017, p6 [13]) 
The remain parts of this research note will be arranged as followed. The next section will introduce the three SDG indicators directly about renewable energy, food supply chain, and sustainable marine fishery. The current limitations and difficulties in data collection and computation for these SDG indicators will also be briefly explained. Section 3 will discuss the use of renewable energy in food supply chain and sustainable marine fishery, with a special emphasis on how renewable energy can contribute to the measurement of related SDG indicators. Some implications for further scientific studies and practiceoriented research, especially the methodological considerations, will also be explored in Section 3 . Section 4 concludes this research note, which outlines the advantages and limitations, and also points out the possible ways forward. This short research note aims to generate more thoughts in this field rather than firsthand empirical evidence, therefore it will not use separate sections to review the literature and the possible data sources such as the SDG Global Database (UN, 2021) [14]. Instead this research note will dialogue with relevant literature in the discussion and implications.

\section{SDGs of renewable energy, food supply chain, and marine fishery}

Renewable energy, food supply chain, and marine fishery have wide presence across SDGs. For example, both SDG 2 (especially SDG Targets 2.3, 2.b, and 2.c) and SDG 12 (in particular SDG Target 12.3) address food supply chain, and marine fishery is a focus of SDG 14 (especially SDG Target 14.7). This research note only introduces the three SDG indicators which are most directly related to renewable energy, food supply chain, and marine fishery.

\subsection{SDG Indicator 7.2.1: Renewable energy share in the total final energy consumption International Energy Agency (IEA), UN} Statistics Division (UNSD), and IRENA monitor the data for SDG Indicator 7.2.1, which has the full name 'Renewable energy share in the total final energy consumption' (IEA, UNSD, and IRENA, 2021, p1) [15]. The indicator can be defined as the proportion of final energy consumption that is obtained from renewable resources, which include hydro, wind, solar, solid biofuels, biogas, liquid biofuels, marine, geothermal, and renewable waste (IEA, UNSD, and IRENA, 2021, p1-2) [15]. The data for this indicator is from national energy balances plus special surveys at different levels (such as industrial surveys and household surveys). The inclusion of both on land and off shore energy consumption brings conveniences to estimate the energy consumption by marine fishing vessels/fleets if needed, especially at country level. Another feature of this indicator is that it measures the quantity of energy consumption and share of renewable energy rather than energy cost, which provides conveniences for cross-country and over-year comparisons as the disruption from energy price fluctuations is minimized. However, this leads to inconveniences when the information of energy cost is required.

In short, SDG Indicator 7.2.1 can be expressed in Equation (1) below:

$R E_{\text {share }}=Q_{R E} / Q_{T} \times 100 \%$

In this equation, $\mathrm{RE}_{\text {share }}$ means the share of renewable energy in total final energy consumption, $\mathrm{Q}_{\mathrm{RE}}$ refers to the quantity of final energy consumption derived from renewable resources, and $\mathrm{Q}_{\mathrm{T}}$ is the total quantity of final energy consumption.

\subsection{SDG Indicator 12.3.1 (b): Food waste index}

SDG Indicator 12.3.1 actually has two components: food loss index and food waste index. Both of them are strongly related to food supply chains. The former is more about the production and processing while the latter is more relevant to the consumption. However, since currently there is very few data for food loss index in the SDG Global Database (UN, 2021) [14], this research note focuses on food waste index instead.

United Nations Environmental Programme (UNEP) is the custodian agency of SDG Indicator 12.3.1 (b). As shown by UNEP (2021, p4) [16], the basis of food waste index is the food waste per capita in a specific year, which is expressed by Equation (2) as below:

Food waste per capita $_{Y}=$ Total food waste $_{Y} /$ Total population $_{Y} \ldots \ldots . . . . . .$. (2)

The subscript ' $\mathrm{Y}$ ' in this equation refers to any specific year. If total food waste in a given year is not available, then it can be estimated by Equation (3) below:

Total food waste $_{Y}=$ Municipal solid waste $_{Y}\left(M S W_{Y}\right) \times$ Share of food waste in $M S W_{Y}$

And Equation (2) can also be replaced by Equation (4) below if total food waste is not easily available in a given year:

Food waste per capita $_{Y}=\left(M S W_{Y} \times\right.$ Share of food waste in $\left.\mathrm{MSW}_{Y}\right)$ /Total population $_{Y}$.

Food waste index in year $\mathrm{Y}$ is the ratio between food waste per capita in year $\mathrm{Y}$ and food waste per capita in a reference year (year 0), or can be expressed in Equation (5):

Food waste index $_{Y}=\left(\right.$ Food waste per capita $_{Y} /$ Food

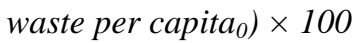




\subsection{SDG Indicator 14.7.1: Sustainable fisheries as a proportion of GDP in small island developing States, least developed countries and all countries}

FAO is the custodian agency of SDG Indicator 14.7.1, which measures sustainable marine fishery's contribution to economy while fishery from in land waters are not included (FAO, 2021b) [17]. It has two parts: the environmental component, which is reflected by 'sustainability multiplier' computed by FAO, and the economic component, which is the share of value added of marine fishery in GDP. Equation (6) below summarizes SDG Indicator 14.7.1:

Sustainable marine fishery's contribution to GDP = (Value added of marine fishery/GDP) $\times$ Sustainability multiplier....

The value added of marine fishery is the gross value of fishes captured from marine sources minus the on board production and processing cost. The cost usually includes the operation expenses of fishing vessels/fleets (such as the energy cost for vessels to go to and return from fishing areas), preserving and processing cost (such as the expenses to run on board refrigerators for fish storage). Equation (6) can also be replaced by Equation (7) below if value added of marine fishery is not directly available:

Sustainable marine fishery's contribution to GDP = Sustainability multiplier $\times$ (Gross value of marine captured fishes - on board production and processing cost)/GDP

A difficulty in the measurement, as shown in Equation (7), is the computation of on board production and processing cost. Not only because it varies across fishing vessels/fleets, but also as a result of the complexity in measuring the on board use of goods and services in the process of fish production and preservation. Since consumption of energy (including renewable energy) is essential for marine fishing activities and also food supply chain, it is able to use SDG Indicator 7.2.1 to assist the measurement and data computation for SDG Indicators 12.3.1 and 14.7.1, which will be discussed in the next section.

\section{DISCUSSION AND IMPLICATIONS}

The three SDG Indicators which are directly related to renewable energy, food supply chain, and sustainable marine fishery are introduced in the previous section. Difficulties in data collection, measurement, and computation are also mentioned. This section briefly discusses the opportunities to use SDG Indicator 7.2.1, which is a Tier 1 indicator that has relatively higher data availability and methodological strengths, to assist the estimation and computation of data for SDG Indicators 12.3.1 and 14.7.1. This can also generate implications for future studies, especially in terms of methodology. Practice-oriented recommendations are also provided.
3.1 Renewable energy in marine fishery: estimating SDG Indicator 14.7.1

The exact measurement of on-board production and preservation costs for fishes harvested from sea is not straightforward. One difficulty is that it is difficult to know the exact amount of energy consumption for fishing vessels/fleets. This is particularly the situation as the fishing vessels/fleets are usually decentralized and have significant varieties (Basurko et al, 2013) [7]. However, with country level data for SDG Indicator 7.2.1, it assists the estimation of energy consumption on board, and therefore contributes to the estimation of data for SDG Indicator 14.7.1.

For a given country, if the share of renewable energy in final energy consumption is known, then it is possible to estimate this figure for marine fishing vessels/fleets. This is of course based on a solid understanding of the country context including the marine fishing vessels/fleets with that country's flag. For example, the overall technological level of that country's marine fishing vessels/fleets should be known. If we can estimate the share of renewable energy consumed on board, then it is able to compute the total energy consumed by fishing vessels/fleets, as the non-renewable energy consumption (such as the fuel consumed by engines) is usually obtainable. Since a significant proportion of cost for fishing activities is the on board energy cost, estimating on board energy consumption via SDG Indicator 7.2.1 could contribute to the computation of data for SDG Indicator 14.7.1. That means, it is able to use Equation (1) to assist the estimation of the on board production and processing cost in Equation (7), as it is usually difficult to have information on the exact total energy consumption by fishing vessels/fleets. In contrast, it is relatively easier to know other on board costs (such as labour cost and depreciation of machines) and the gross value of captured fishes.

\subsection{Renewable energy in food supply chain: estimation of food waste}

Although it looks that renewable energy does not have a presence in computing food waste, as shown in Equation (2) and Equation (5), it may still contribute to the estimation of food waste if the data is not directly available. For example, in Equation (3) and Equation (4), if we know the proportion of MSW that comes from energy sector (including renewable energy), then it would be possible to estimate the total amount of MSW in a given year. This could be easier than seeking data for MSW in direct approaches. However, it is essential to note that share of (renewable) energy waste in MSW is based on experience and estimation, similar as the share of food waste in MSW. That means, in comparison with direct approaches, the estimation is less reliable and straightforward although it is relatively easier for data collection and computation. 
Suyu Liu., Sch Bull, Jan, 2022; 8(1): 10-16

Furthermore, since the wider deployment of renewable energy may lead to competition with other uses of resources (including food supply and consumption) in some contexts, as demonstrated by IRENA and FAO (2021) [4], we may need to notice that the changes of share of renewable energy in total energy consumption (as monitored by SDG Indicator 7.2.1) may cause the fluctuations of total food waste and/or the share of food waste in MSW. Therefore the measurement and computation of data for SDG Indicator 12.3.1 (b) can be affected by SDG Indicator 7.2.1. This generates some further thoughts on the interactions across SDGs (including SDG indicators), although this short research note cannot use empirical evidence to demonstrate such interactions.

\subsection{Implications and recommendations}

The plausibility of using SDG Indicator 7.2.1 to assist the measurement and computation of data for SDG Indicators 12.3.1 (b) and 14.7.1 is discussed above. This generates some thoughts on the possibility of future research in this field, as well as practiceoriented recommendations.

This research note encourages further studies on the interactions across SDGs (including SDG indicators). Although no empirical data was analyzed in this research note, the theoretical and methodological discussion still shows that the interactions across SDGs may exist. For example, the changes of share of renewable energy in total energy consumption (SDG Indicator 7.2.1) may affect the amount of food waste, which is the basis for computing food waste index (SDG Indicator 12.3.1). This extends some previous research which focuses on interactions across different dimensions of SDGs, such as the economic and the environmental dimensions (e.g., Liu, 2020) [18]. It shows that even within the same aspect (such as environmental aspect) of SDGs, interactions across different SDGs (including different SDG indicators) may still exist. Future studies could generate more insights of such interactions.

More in-depth empirical studies, especially at country level, are also encouraged. This is not only because of the SDG Global Database mainly has country level data (UN, 2021) [14], but also due to the relative convenience in understanding the specific context at country level than regional or global level. The important of country context in research about SDGs is demonstrated by existing literature (e.g., Huaccho Huatuco and Ball, 2019) [19]. International comparisons are viable with adequate consideration of disparities in country contexts including national statistical capacity (e.g., Liu, 2021) [20], which in practice may affect the estimation of data for SDG indicators.
More sophisticated modelling techniques can be applied into future research in this field. For example, since the SDG Global Database has data for SDG Indicator 7.2.1 in more than 100 countries over 10 years until 2018 (UN, 2021) [14], time-series analysis and panel data analysis could be conducted. Data for other socioeconomic and environmental indicators may be obtained from World Bank Open Data to support the analysis and control essential variables (World Bank, 2021) [21].

In terms of practice, this research note also generates some implications and recommendations. Since the interactions across SDGs (including SDG indicators) are observed, it is recommended for policy makers to adopt integrated and holistic approaches to support the sustainable development. For example, being consistent with IRENA and FAO (2021) [4], this research note supports the further integration of foodenergy systems. Recent studies on Food-Energy-Water Nexus provide valuable insights into policy recommendations of holistic approaches for sustainable development (e.g., Yuan and Lo, 2022) [22].

Effective policies and actions for sustainable development, including supporting renewable energy in food supply chain and marine fishery, must be consistent with specific country context. The proper interpretation and application of SDG data is not possible without a solid knowledge of the country context. In addition, understanding of the country context is essential to properly balance different aspects of sustainable development and adequately arrange priorities. This is because in practice, renewable energy, food supply chain, and marine fishery are usually under the management of different ministries (such as environment, energy, agriculture, ocean, and commerce ministries), and these ministries often have competing or even conflicting priorities. Therefore, the proper balance of these different priorities strongly depends on the country context. Environmental Kuznets Curve is a good example which generates insights into the balance of these priorities (e.g., Liu, 2020) [18].

Practical efforts to improve data collection and information update should be strongly encouraged. Although the data availability in the SDG Global Database has been improved, data limitation still hinders the adequate application of renewable energy in the agri-food sector including the food supply chain and marine fishery (IRENA and FAO, 2021) [4]. Modern technology such as geospatial mapping tools and energy modelling packages can be adopted to improve the development of renewable energy in food supply chain and marine fishery, and also provide reliable evidence to support holistic policy-making. Enhancement of national statistical capacities can be observed via monitoring SDG 17 (especially SDG Indicators 17.18.1 
Suyu Liu., Sch Bull, Jan, 2022; 8(1): 10-16

and 17.19.1), which again demonstrates the possible interactions across SDGs.

\section{CONCLUSION AND THE WAY FORWARD}

This short research note is an early attempt to explore renewable energy in food supply chain and marine fishery with the angle of SDGs. It identifies the possible opportunities to use SDG Indicator 7.2.1, which measures the share of renewable energy in total energy consumption, to assist the measurement of and data computation for SDG Indicators 12.3.1 (b) and 14.7.1. With a theoretical examination of the core definitions and computation methods of these indicators, it is observed that knowing the share of renewable energy in total energy consumption can contribute to the estimation of data for on board energy consumption of fishing vessels/fleets, as well as the data for food waste. This is particularly useful when these data are not directly available. Therefore, renewable energy data (SDG Indicator 7.2.1) is helpful for the estimation of data for SDG Indicators 12.3.1 (b) and 14.7.1.

Implications for future studies can be generated from this research note. For example, further studies on the interactions across SDGs, even within the same dimension of SDGs, should be encouraged. In addition, this research note calls for more in-depth empirical analysis based on country level data, which can be obtained from the SDG Global Database. More sophisticated analytical techniques such as time-series and panel data analysis could also be conducted if disparities in country contexts are properly considered. This research note is an initial output of a series of studies in the author's plan, and therefore more in-depth analysis in this field can be expected in the coming future.

This short research note is not free from limitations. Firstly, it only explores renewable energy in food supply chain and marine fishery in a methodological approach without using empirical data. Therefore, the findings are based on theoretical analysis rather than empirical evidence. Future research including the author's studies can gradually reduce this gap. Secondly, although the interactions across SDGs (including SDG indicators) are stressed, it is unable to further examine these interactions in this research note because of data and space restrictions. Thirdly, although this research note enriches the scientific knowledge in this field, it is unable to have a thorough literature review due to limited spaces. In short, this research note is an early attempt to use the perspective of SDGs to explore renewable energy in food supply chain and marine fishery by examining the methodological connections across SDG Indicators 7.2.1, 12.3.1 (b) and 14.7.1. The main objectives of the research note include enriching the current knowledge, generating practical implications, and calling for more in-depth future studies in this field. It is far from perfect and thus it provides opportunities for further research related to this topic, including the author's own research in the coming future.

\section{ACKNOWLEDGEMENT}

The author is grateful to the valuable insights from current and former colleagues and peers in the United Nations and its related departments, organizations, agencies, and/or observers. The views expressed in this research note are the author's unless otherwise specified. Unless otherwise mentioned, the contents in this research note do not reflect any official stance or statement of the United Nations and its related departments, organizations, agencies, and/or observers, including FAO, IRENA, and UNEP. This research note is not an official output of the above-mentioned organizations.

\section{REFERENCES}

1. IRENA. (2021). World Energy Transitions Outlook: $1.5^{\circ} \mathrm{C}$ Pathway (Executive Summary), International Renewable Energy Agency, Abu Dhabi.

2. Karekezi, S., \& Kithyoma, W. (2002). Renewable energy strategies for rural Africa: is a PV-led renewable energy strategy the right approach for providing modern energy to the rural poor of subSaharan Africa? Energy Policy, 30(11-12), 10711086.

3. IRENA. (2020). The post-COVID recovery: An agenda for resilience, development and equality, International Renewable Energy Agency, Abu Dhabi.

4. IRENA and FAO (2021). Renewable energy for agri-food systems - Towards the Sustainable Development Goals and the Paris agreement. Abu Dhabi and Rome.

5. FAO. SDG Indicator metadata - 12.3.1 (a), 2021a.

https://unstats.un.org/sdgs/metadata/files/Metadata -12-03-01A.pdf

6. Jensen, J. K., \& Govindan, K. (2014). Assessment of renewable bioenergy application: a case in the food supply chain industry. Journal of Cleaner Production, 24, 254-263.

7. Basurko, O. C., Gabiña, G., \& Uriondo, Z. (2013). Energy performance of fishing vessels and potential savings. Journal of Cleaner Production, 54, 30-40.

8. Lu, Z., \& Wang, R. (2016). Experimental performance study of sorption refrigerators driven by waste gases from fishing vessels diesel engine. Applied Energy, 174, 224-231.

9. Liu, S. (2022 forthcoming). Sustainable Fishery and Renewable Energy in Perspective of Sustainable Development Goals (SDGs): Revisiting SDG Indicators 7.2.1 and 14.7.1. 
European Journal of Sustainable Development.

10. Le Blanc, D. (2015). Towards Integration at Last? The Sustainable Development Goals as a Network of Targets. Sustainable Development, 23(3), 176187.

11. UN. (2020). The Sustainable Development Goals Report 2020. New York, the United States of America.

12. IAEG-SDGs. (2021). Tier Classification for Global SDG Indicators as of 29 March 2021. https://unstats.un.org/sdgs/files/Tier\%20Classificat ion $\% 20$ of $\% 20$ SDG $\% 20$ Indicators_29\%20Mar\%20 2021_web.pdf

13. International Council for Science (ICSU). (2017). A Guide to SDG Interactions: from Science to Implementation [D.J. Griggs, M. Nilsson, A. Stevance, D. McCollum (eds)]. International Council for Science, Paris.

14. UN. (2021). SDG Global Database. https://unstats.un.org/sdgs/UNSDG/IndDatabasePa ge

15. IEA, UNSD, and IRENA. (2021). SDG indicator metadata 7.2.1. https://unstats.un.org/sdgs/metadata/files/Metadata -07-02-01.pdf

16. UNEP. (2021). SDG indicator metadata- 12.3.1 (b).
https://unstats.un.org/sdgs/metadata/files/Metadata -12-03-01B.pdf

17. FAO (2021). SDG indicator metadata - 14.7.1. https://unstats.un.org/sdgs/metadata/files/Metadata -14-07-01.pdf

18. Liu, S. (2020). Interactions between industrial development and environmental protection dimensions of Sustainable Development Goals (SDGs): Evidence from 40 countries with different income levels. Environmental \& Socio-economic Studies, 8(3), 60-67.

19. Huaccho Huatuco, L., \& Ball, P. D. (2019). The quest for achieving United Nations Sustainability Development Goals (SDGs): Infrastructure and innovation for responsible production and consumption. RAUSP Management Journal, 54 (3), 357-362.

20. Liu, S. (2021). Child mortality and water stress under the framework of Sustainable Development Goals (SDGs): Evidence from twenty developing countries. Present Environment \& Sustainable Development, 15(1), 49-58.

21. World Bank (2021). World Bank Open Data. https://data.worldbank.org/

22. Yuan, M. H. \& Lo, S. L. (2022). Principles of food-energy-water nexus governance. Renewable and Sustainable Energy Reviews, 155, 111937. 